\title{
Toward a Realistic Science of Environments
}

\author{
Barry Smith \\ phismith@acsu.buffalo.edu \\ Preprint version of paper in Ecological Pschology 21 (2), April-June 2009, 121-130
}

\section{The Ride on Lake Constance}

If mind is a creature of adaptation, then our standard representationalist theories of mind are in need of revision. For such theories are inspired by Cartesian ways of thinking. They thus conceive the subject of mental experience in isolation from any surrounding physico-biological environment and do not grapple with the interconnections between the world of human thought, feeling and action and the environment of human behavior as this is described by physics and evolutionary biology. Mind is an all-or-nothing affair, that is not coherently integrated with the causal-energetic world of what happens and is the case.

One group of more holistically inclined thinkers, forming what is commonly referred to as the Berlin School of Gestalt psychology, offer the beginnings of a more adequate approach. The members of this school, especially Max Wertheimer, Wolfgang Köhler, Kurt Koffka, and Kurt Lewin, sought to understand the relations between mental acts and external objects as participants in a larger complex of interactions between subjects and objects in a common physical and biological environment. Koffka and Lewin in their turn influenced the American psychologist J. J. Gibson, and it is against this background that Gibson's ecological psychology was born.

\section{The Problem of the 'Two Worlds'}

The Gestalt psychologists had no qualms in accepting the reality of the world described in physical theories, and they were among the first to investigate the relations between mental experiences and associated processes in the brain. When turning to the external environment of human behavior and perception, however, 
they still embraced a Cartesian approach and saw this environment as something like a manifest image constructed by the human subject. Hence they were left with the problem of explaining the relation between this constructed environment and the world of physics.

To see the nature of the problem, it will be useful to quote an important passage from Koffka's Principles of Gestalt Psychology in which a fateful distinction between two environments - the psychological (or 'behavioral') and the physical (or 'geographic') - is introduced:

On a winter evening amidst a driving snowstorm a man on horseback arrived at an inn, happy to have reached shelter after hours of riding over the wind-swept plain on which the blanket of snow had covered all paths and landmarks. The landlord who came to the door viewed the stranger with surprise and asked him whence he came. The man pointed in the direction straight away from the inn, whereupon the landlord, in a tone of awe and wonder, said: 'Do you know that you have ridden across the Lake of Constance?' At which the rider dropped stone dead at his feet.

In what environment, Koffka asks, did the behavior of the stranger take place?

The Lake of Constance. Certainly [... and it is] interesting for the geographer that this behaviour took place in this particular locality. But not for the psychologist as the student of behaviour.

The latter, Koffka concludes, will have to say that there is a second sense to the word 'environment,' according to which

our horseman did not ride across the lake at all, but across an ordinary snow-swept plain. His behaviour was a riding-over-aplain, but not a riding-over-a-lake. (Koffka 1935, pp. 27f.)

How, then, are we to understand the relationship between the physical and the psychological environment? The tale of the ride across Lake Constance tells us that we cannot conceive them as identical in every case. But we cannot say, either, that they are always distinct (and thus embrace a 'two-world' hypothesis). Certainly we would then gain the advantage of a uniform domain for psychological science; but we would also face the problem of explaining how this psychological domain (and hence our psychological experience) might ever come into contact with the domain of physics. Perhaps, then, we can defend the view according to which the two environments are connected via some sort of partial 
identity relation. Identity obtains in those cases where there is a match between experience and objects, but fails in cases of mismatch of the sort described by Koffka. The problem with this view, however, is that it would imply a peculiar ontological heterogeneity of psychological experiences (which from the perspective of the experiencing subject would yet appear homogeneous). For it would imply that we would somehow, in the course of our mental experience, be crossing back and forth between genuine interaction with physical reality on the one hand and quasi-solipsistic concern with our own psychological creations on the other. It would imply also a corresponding disunity of the domain of psychological science.

The Berlin Gestaltists embraced the first of these two alternatives; that is, they embraced the two-world (two-environment) thesis. They were consequently not able to come to a coherent account of the relationship between the environment of psychologically experienced objects and the world of physical things. This is true even of the most sophisticated theorists of the psychological environment such as Kurt Lewin and Fritz Heider. For them, too, the psychological environment is something dependent upon the ego (something that is present even in dreams: Heider 1959), and thus not something that could be accepted as a part of physical reality. This view survives today in philosophical psychology where it is described under the heading 'methodological solipsism' (Fodor 1980). The issue of the relationship between psychological and physical phenomena is bracketed in order to ensure an ontologically uniform domain for psychological science within which both true and false beliefs and both veridical and non-veridical perceptual phenomena can enjoy equal rights in a single homogeneous stream of representations.

\section{Scheler's Doctrine of the Milieu: An Illustration of How Things Go Wrong} To see the nature of the problem from another perspective it is useful to look at the thinking of the phenomenologist Max Scheler on what he called the 'milieu' of practical life, which anticipates the later, and more influential theory of the 'life world' developed by Hussserl (1954). The things which are relevant to our acting, Scheler tells us, in describing his own version of the Gestalt's psychological environment,

have of course not the slightest to do either with Kant's 'thing in itself' or with the objects conceived by science (through the supposition of which science 'explains' natural facts). The sun of the milieu of human beings is not the sun of astronomy. The meat that is stolen, bought, or what have you, is not a sum of cells and tissues with the chemicophysical processes which take place within them. The sun of the milieu is different at the 
North Pole, in moderate zones, and at the equator, and its beams are felt as different beams. (Scheler 1954, p. 158f., Eng. trans., p. 139)

The problem with this passage is clear. As schoolboys with microscopes know, meat that is stolen and bought does most certainly possess cells and tissues which undergo chemicophysical processes. It simply cannot be the case that the things in our practical, commonsensical environment have 'not the slightest' to do with the objects conceived by science.

Electrical and magnetic currents, Scheler wants to hold, may affect me 'objectively;' but they do not belong to my milieu, which comprehends 'only that which I effectively experience.' But is it really possible to mark out a 'world' - a psychological environment - of what is effectively experienced without at the same time letting in all manner of cells, tissues, fields, currents, and the chemicophysical properties relating thereto?

One option pursued by Scheler is to see milieu-things as being in some sense intermediate between persons and the 'objective' reality that is studied by physics, as belonging to an intermediate realm 'lying between our perceptual content and its objects on the one hand and those objectively thought objects on the other.' (Scheler 1954, p. 159, Eng. trans. p. 140). But how, then, to provide a satisfactory account of the relationship between such milieu-things and their physical counterparts?

For Scheler the milieu is something holistic: it is not the sum of things I perceive or take an interest in or pay attention to. Rather, I can be intentionally related only to what already belongs to my milieu. The milieu is a fund of objects, comprising all of that of which I have the ability to take account in my practical day-to-day dealings with the world. It can include not only food, utensils, people, buildings, the words which I read on the page, but also the laws which I obey or disobey, the value-qualities which make things attractive or repulsive, and other features which seem to belong entirely outside the realm of material things. Thus one and the same landscape presents different milieux to one who recognizes the authorities which prevail within it, to a criminal, and to one who is an enemy in time of war. The same forest is likewise a different milieu to a forester, a hunter, a hiker, as also to a deer or a lizard. (Op. cit., p. 161f., Eng. trans. p. 142f.)

\section{Ecological Realism}

With the work of Gibson we meet a new approach to this problem, in which the external, physical, geographical environment is at last given its due. To a much greater degree than is manifest in even the most radical Gestaltist writings, 
Gibson emphasizes that normal psychological experience is to be understood not in terms of a succession of relations between interior mental acts on the one hand and objects in some special 'realm' on the other, but rather in terms of something like a topological nesting, whereby the sentient organism is housed or situated within a surrounding environment of which it serves as interior boundary. ${ }^{1}$

Perceptions and actions are to be understood, from this perspective, as mere dependent features of an encompassing organism-environment relation, whereby both organism and the environment are to be conceived as falling within the realm of physics. In perception, as in action, from the Gibsonian point of view, we are caught up with the very things themselves in the surrounding world, and not with 'sense data' or 'representations'. Perception is not a matter of the processing of sensations. Rather, it is part of that direct linkage between the perceiving organism and its environment which grows out of the fact that, in its active looking, touching, tasting, feeling, the organism as purposeful creature is bound up with those very objects-the ripened fruit, the crumpled shirt, the empty glass, the broken spear-which are relevant to its life and to its tasks of the moment.

Gibson thus embraces a radically externalistic view of mind and action. We have not a Cartesian mind or soul, with its interior theater of 'contents' and the consequent problem of explaining how this mind or soul and its psychological environment can succeed in grasping physical objects external to itself. Rather, we have a perceiving, acting organism, whose perceptions and actions are always already inextricably intertwined with the parts and moments, the things and surfaces, of its external environment.

\section{The Ontology of the Niche}

For Gibson, reality is a complex hierarchy of inter-nested levels of parts and subparts: molecules are nested within cells, cells are nested within leaves, leaves are nested within trees, trees are nested within forests, forests are nested within Special Federal Forest Protection Zones, and so on. (Gibson 1986, p. 101.) Each type of organism is tuned in its perception and action to objects on specific levels within this complex hierarchy - to objects ('affordances') which are the environmental correlates of innate and learned traits on the side of the organism.

\footnotetext{
${ }^{1}$ Important elements of this approach, especially as concerns the way in which individual human beings within socially determined physical-behavioral settings (for example in schools, factories, churches) were developed by Roger Barker, a contemporary of Gibson's who applied ecological psychology to the world of human behavior. See Heft 2001, Schoggen 1989, and Smith 2001. Schoggen describes physical-behavioral settings as consisting of 'highly structured, improbable arrangements of objects and events that coerce behavior in accordance with their own dynamic patterning.' (1989, p. 4) On a formal theory of organism-environment relations that is rooted in Gibsons's and Barker's ideas, see Smith and Varzi 1999 and 2002.
} 
These environmental correlates together form what Gibson calls the organism's 'ecological niche'. A niche is that into which an animal fits (as a trained hand fits into a well-fitting glove, as trained eyes fit well onto a page of words). The niche is that in relation to which the animal is habituated in its behavior. (Gibson 1986, p. 129.) It embraces not only things of different sorts, but also shapes, textures, boundaries (surfaces, edges), all of which are organized in such a way as to enjoy affordance-character for the animal in question in the sense that they are relevant to its survival. The given features motivate the organism; they are such as to intrude upon its life, to stimulate the organism in a range of different ways.

The perceptions and actions of human beings are tuned to the characteristic shapes and qualities and patterns of behavior which form their environments. The scope of this attunement is in our case extended further via artifacts, such as microscopes and telescopes, and via cultural phenomena such as languages and institutions of law and politics. To learn a language is in part to extend the range of objects in relation to which we are able spontaneously to adjust our behavior and thus it is to extend radically the types of niche or setting into which we can spontaneously fit.

\section{Is Gibson a Realist?}

Human environments, like the environments of all other animals, are parts of physical reality and this is so however far they may be extended through artifacts of different sorts. Yet still, a science of human environments will look very different from any branch of physics. This is not because environments form a separate psychological reality of subjective constructs. Rather, it is because what belongs and what does not belong to the environment of each given organism is dependent in non-rule-governed ways on that organism's location, background, traits, needs, and so forth. The delineation between the environmental and the extra-enviromental is on the one hand spatial - no part of Minsk is part of my environment of the moment when I am asleep in Buffalo. But it is also a matter of granularity: the molecules in my bathroom mirror are, unless I am engaging in specific molecule-related activities, are not part of the environment of my morning ablutions. ${ }^{2}$

As Gibson saw, we face a challenge to develop a realist science of environments which will be 'consistent with physics, mechanics, optics, acoustics, and chemistry' by taking seriously the idea that ecological facts are 'facts of higher

\footnotetext{
${ }^{2}$ On the puzzles raised here - where $x$ is part of my environment but not the parts of $x$ - see Smith 2003. On the underlying formal theory of granular partitions see Bittner and Smith 2003.
} 
order that have never been made explicit by these sciences and have gone unrecognized.' (Gibson 1979, p. 17) He uses the term 'ecology' precisely in order to designate the discipline that should encompass these higher-order facts; it is 'a blend of physics, geology, biology, archeology, and anthropology, but with an attempt at unification' on the basis of the question: what can stimulate the organism? (Gibson 1966, p. 21)

Gibson thus stands out from the bulk of contemporary psychologists in rejecting representationalism in favor of what he calls 'direct realism', a position according to which we are, as a result of adaptation, bound up directly and spontaneously in our normal psychological experience with the objects themselves in the physical world - because we ourselves form part of the physical environment.

There is a puzzle, however. For Gibson's ecological perspective is in other respects very close to phenomenological theories of the environment like the Schelerian theory referred to above, which have been held to dictate precisely a representationalist reading. In an important paper entitled "Is Gibson a Relativist?" Stuart Katz helps us to understand how this apparent conflict could have arisen by drawing attention to passages in Gibson's work which seem to negate a realist interpretation of his views and thus draw him closer to the phenomenologists. Katz points in particular to the following characteristic statements from Gibson's Ecological Approach to Visual Perception:

animal and environment make an inseparable pair. Each term implies the other. No animal could exist without an environment surrounding it. Equally, although not so obvious, an environment implies an animal (or at least an organism) to be surrounded. $(1979$, p. 8$)$

The affordances of the environment are what it offers the animal, what it provides or furnishes, whether for good or ill. - I mean by [affordance] something that refers to both the environment and the animal in a way that no existing term does. It implies the complementarity of the animal and the environment. (1979, p. 127)

... an affordance is neither an objective property nor a subjective property; or it is both if you like. An affordance cuts across the dichotomy of subjective-objective. - It is both physical and psychical, yet neither (1979, p. 129). 
These passages dictate, according to Katz, a reading of Gibson according to which different species live in different worlds. Water is for you and me a substance; for fish it is a medium which substances inhabit. Hence the question arises:

Do terrestrial animals perceive water correctly and aquatic species incorrectly, or vice versa? Gibson as relativist tells us no. Each lives in a different world and, complementarily, each perceives differently. Water is a substance in one world and a medium in another; it is not absolutely substance, nor is it absolutely medium. 'The animal and its environment, remember, are reciprocal terms.' One could never say what water is, without saying for whom it is, and conversely. (Katz 1987, p. 120)

\section{Reasons for Representationalism}

Whether valid or not, Katz's argument is significant. If it is valid, then this implies that phenomenologists such as Husserl or Scheler can claim a hitherto unrecognized ally among experimental psychologists. If, on the other hand, the argument is flawed, then in coming to understand why this is so, we will discover which modifications of standard Husserlian views must be made if we are to bring them into harmony with Gibsonian realism.

To see whether Katz's argument is valid or not, we note that there are two principal motivations for representationalist views of perception: (1) the problem of perceptual error, and (2) the problem of apparent global incompatibilities between different systems of representations.

The existence of perceptual error, according to familiar arguments (involving bent sticks and like phenomena), reveals that perception itself cannot be solely a product of sensory inputs. It tells us that, on occasion at least, for example in cases of hallucination, perceptual objects are in some sense or to some degree created or constituted by or with the help of the perceiver. A representationalist, again, is one who holds that the objects that are given in perception are always constructed or constituted in this sense (hence they belong to a special world, a world of representations). The representationalist is able to do justice to the fact of perceptual error without abandoning the goal of a unified theory of perception, but only at the price of cutting off her theory from any roots in the real world of mind-independent objects. The realist solution to the problem of error, on the other hand, denies that what is phenomenologically experienced as the unitary stream of phenomena of perception is in fact a unitary matter. Rather, it distinguishes two types of perceptual setup, and correspondingly two distinct tasks for the theory of perception. On the one hand is the task of providing a 
theory of perception in the strict sense - a theory of successful, veridical, worldembrangled perception of the normal sort. On the other hand is the quite different task of giving an account of perceptual error (of the different types of shortfall from this standard, veridical case). There is a theory of smooth running in the realm of perception, and a supplementary account of accidents and breakdowns.

A second motivation for representationalism might be formulated as follows: our common-sense perceptual space has a Euclidean structure (or a structure closely related thereto); the space of the physicist has another, quite different structure; and it may well be that the perceptual spaces of mice, of spiders, of clams, have other structures again. Not all of these structures can be true of space as it is in itself. Hence, the argument goes, our (and the mouse's, and the spider's) perceptual spaces are mere 'representations'. And what goes for space holds for other features of the manifold environments of perception, too - so that it is as if each species lives in its own special world.

It is a constructivist, relativist, representationalist, projectivist, methodologically solipsist, Kantianist, Uexküllist conclusion of this sort which Katz attributes to Gibson. But, to remain with Katz's own example, space (as we may here assume) is a continuum. Like all continua it can be partitioned in a range of mutually incompatible ways (as a cheese can be sliced in such a way as to produce either triangular or rectangular or disk-shaped segments, but not all of these at once). In principle, therefore, all members of a family of mutually conflicting 'perceptual spaces' may well turn out to be compatible after all, if they can be interpreted as expressing distinct partitions, for example partitions on different levels of granularity, of one and the same reality. (Bittner and Smith 2003) In this way the second motive for representationalism may be resisted, too, and therewith also for a representationalist reading of Gibson. In full conformity with the realist perspective, different languages, different theories, and different families of organisms are able to generate their own precisely fitting partitions of one single reality. The various animal behavior-systems generate partitions of reality into their own ecological niches. But these are not separate worlds. Rather, they are partitions of one and the same world, effected for different purposes and at different levels of granularity.

The ultimate common ontology governing these environments will be scientific, but it will have room not only for physics but also for mesoscopic structures built up on the basis of physics, including structures of the type to which human behaviour and perception are tuned. But to do justice to this complex edifice, the 
realistic science of organisms, biology, will need as its counterpart a realistic science of environments.

\section{References}

Bittner, Thomas and Smith, Barry 2003 "A Theory of Granular Partitions", Foundations of Geographic Information Science, Matthew Duckham, Michael F. Goodchild and Michael F. Worboys (eds.), London: Taylor \& Francis, 2003, 117151.

Fodor, Jerry 1980 "Methodological Solipsism Considered as a Research Strategy in Cognitive Psychology," Behavioral and Brain Sciences, 3, 63-73.

Gibson, J. J. 1966 The Senses Considered as Perceptual Systems, London: George Allen and Unwin.

Gibson, J. J. 1979 The Ecological Approach to Visual Perception, Boston: Houghton-Mifflin, repr. 1986, Hillsdale, NJ: Lawrence Erlbaum.

Heft, Harry 2002 Ecological Psychology in Context: James Gibson, Roger Barker, and the Legacy of William James's Radical Empiricism, Mahwah, NJ: Lawrence Erlbaum.

Heider, Fritz 1959 "The Description of the Psychological Environment in the Work of Marcel Proust," in Heider, On Perception and Event Structure, and the Psychological Environment, Selected Papers (Psychological Issues, Vol. 1, No. 3), New York: International Universities Press, 85-107.

Husserl, Edmund 1954 Die Krisis der europäischen Wissenschaften und die transzendentale Phänomenologie. Eine Einleitung in die phänomenologische Philosophie, W. Biemel, ed. (Hua VI), The Crisis of European Sciences and Transcendental Phenomenology: An Introduction to Phenomenological Philosophy, translated by David Carr, Evanston IL: Northwestern University Press, 1970.

Katz, Stuart 1987 "Is Gibson a Relativist?", in A. Costall and A. Still, Cognitive Psychology in Question, Brighton: Harvester, 115-127.

Koffka, Kurt 1935 Principles of Gestalt Psychology, London: Routledge and Kegan Paul. 
Scheler, Max 1954 Der Formalismus in der Ethik und die materiale Wertethik, 4th edition, Bern: Francke, English translation by M. S. Frings and Roger L. Funk as Formalism in Ethics and Non-Formal Ethics of Value, Evanston: Northwestern University Press, 1973.

Schoggen, P. 1989 Behavior Settings. A Revision and Extension of Roger G. Barker'sEcological Psychology,Stanford: Stanford University Press.

Smith, Barry 2001 "Objects and Their Environments: From Aristotle to Ecological Psychology", in Andrew Frank, Jonathan Raper and Jean-Paul Cheylan (eds.), The Life and Motion of Socio-Economic Units, London: Taylor and Francis, 2001, 79-97.

Smith, Barry 2004 “Carving Up Reality”, in M. Gorman and J. Sanford (eds.), Categories: Historical and Systematic Essays, Washington: Catholic University of America Press, 225-237.

Smith, Barry and Varzi, Achille 1999 “The Niche”, Noûs, 33: 2, 198-222.

Smith, Barry and Varzi, Achille 2002 "Surrounding Space: The Ontology of Organism-Environment Relations", Theory in Biosciences, 121, 139-162.

Uexküll, Jacob von 1928 Theoretische Biologie, Berlin: J. Springer. 